\title{
CƠ CHẾ PHÂN TỬ CỦA TÍNH KHÁNG CEPHALOSPORIN CỦA NEISSERIA GONORRHOEAE THU THẠP TẠI VIẸT NAM NĂM 2019 - 2020
}

\author{
Trịnh Minh Trang ${ }^{1,2} \otimes$, Nguyễn Thị Tâm ${ }^{3}$, Lê Viết Thanh ${ }^{4}$ \\ Phạm Thị Minh Phương', Phạm Thị Lan ${ }^{1,2}$, H. Rogier van Doorn ${ }^{3}$ \\ ${ }^{1}$ Bệnh viện Da liễu Trung Ương \\ ${ }^{2}$ Trường Đại Học Y Hà Nội
}

${ }^{3}$ Đơn Vị Nghiên cứu lâm sàng Đại học Oxford, Hà Nội, Việt Nam ${ }^{4}$ Viện Nghiên cứu sinh học Quadram, Trung tâm nghiên cứu Norwich, Norwich, Norfolk, Anh Quốc

Vi khuẩn lậu Neisseria gonorrhoeae (NG) kháng cephalosporin ngày càng gia tăng. 35 chủng NG kháng cephalosporin thu thập từ 3 Bệnh viện Da liễu tại Việt Nam được giải trình tự genome để xác định co chế phân tử của kháng thuốc. Kết quả ghi nhận 13/35 chủng thuộc ST1901, 11/35 chủng thuộc ST 13871. Có 16 loại gen kháng. 74\% chủng mang gen khảm penA 60.001, 11\% mang gen khảm penA 10.001. Các allen penA chứa 6 đột biến chính gây kháng cephalosporin phổ rộng (A311V, T483S, A501P, G545S, I312M và V316T) và nhiều đột biến mới. $74,2 \%$ chủng mang gen mtrR. 100\% chủng mang đột biến mất Adenin trên mtR promoter. Mức độ kháng ceftriaxone tương đồng các chủng FC428 nhưng mức kháng cefixime thấp hơn. Các chủng NG (ST1901 và ST 13871) phân bố chủ yếu ở phía nam Việt Nam, liên quan đến chủng kháng cephalosporin phát hiện đầu tiên tại Nhật Bản và hiện đã lan rộng nhiều nơi. Phần lớn chủng mang allen khảm penA mới và gen $m$ trR/mtrR promoter với các đột biến kháng cephalosporin đặc trưng và có thêm nhiều đột biến mới.

Từ khóa: Cephalosporin, gen kháng, đột biến, MLST, vi khuẩn lậu.

\section{I. ĐẠT VẤN ĐÊ}

Bệnh lậu là bệnh lây truyền qua đường tình dục phổ biến thứ 2 sau nhiễm Chlamydia trachomatis. Tổ chức $\mathrm{Y}$ tế thế giới (WHO) 2018 thống kê có hàng triệu ca lậu mới hàng năm. ${ }^{1}$ Bệnh lậu gây nhiễm trùng cơ quan sinh sản và có thể dẫn đến vô sinh ở cả hai giới. Vi khuẩn lậu đã kháng với hầu hết kháng sinh cổ điển như sulfonamide, penicillin, tetracycline, macrolide và fluoroquinolone. Hiện nay, phác đồ ceftriaxone hoặc cefixime phối hợp với azithromycin được WHO khuyến cáo cho điều trị lậu. Tuy nhiên, các chủng NG kháng

Tác giả liên hệ: Trịnh Minh Trang

Bệnh viện Da liễu Trung ương

Email: trangtm4@gmail.com

Ngày nhận: 02/12/2021

Ngày được chấp nhận: 20/12/2021 cephalosporin phổ rộng (extended spectrum cephalosporin - ESC) và giảm nhạy cảm với azithromycin đang gia tăng. ${ }^{2}$

Chủng NG kháng cefixime được xác định đầu tiên ở Nhật Bản từ năm 1995. Chủng kháng ceftriaxone xuất hiện khoảng 10 năm trở lại đây. ${ }^{3}$ Đáng chú ý, chủng NG kháng ceftriaxone gây ra bởi gen penA 60.001 thuộc dòng chủng FC428 lần đầu được phân lập tại Nhật Bản năm 2015 đã lan rộng ra nhiều khu vực trên thế giới như Châu Âu, châu Á, Úc và Canada. ${ }^{4}$ Tại Việt Nam, khảo sát của LV Hưng và cộng sự ghi nhận các chủng NG giảm nhạy cảm và kháng ESC, nhất là ceftriaxone có xu hướng tăng. ${ }^{5}$ Chúng tôi giải trình tự toàn bộ genome của 35 chủng NG kháng ESC (ceftriaxone và hoặc cefixime) để xác định cơ chế phân tử của tính kháng. 


\section{II. ĐÓI TƯợNG VÀ PHƯƠNG PHÁP}

\section{Phương pháp}

Nghiên cứu mô tả.

\section{2. Đối tượng}

Chủng NG kháng ceftriaxone và hoặc cefixime trên kháng sinh đồ, thu thập từ bệnh nhân nam, nữ bị viêm niệu đạo hoặc viêm cổ tử cung do lậu tại Bệnh viện Da liễu Trung ương, Bệnh viện Da liễu thành phố HCM và Bệnh viện Da liễu Đà Nẵng từ năm 2019 - 2020.

\section{Cỡ mẫu}

35 chủng NG.

\section{Các bước tiến hành}

Bệnh phẩm viêm niệu đạo hoặc viêm cổ tử cung do lậu được thu thập tại Hà Nội (104 mẫu), thành phố Hồ Chí Minh (267 mẫu) và Đà Nẵng (56 mẫu). Tại 03 điểm nghiên cứu này, với mỗi mẫu, chúng tôi thực hiện:

- Thu thập thông tin về nhân khẩu học và yếu tố liên quan ca bệnh.

- Nuôi cấy vi khuẩn lậu trên môi trường Thayer Martin và định danh vi khuẩn lậu bằng test sinh vật hóa học (catalase dương tính, oxidase dương tính và chuyển hóa đường maltose âm tính).

- Kháng sinh đồ khoanh giấy khuyếch tán (Oxoid, UK) đối với kháng sinh penicillin, tetracycline, nalidixic acid, ciprofloxacin, spectinomycin và Etest (Biomerieux) đối với kháng sinh azithromycin, cefixime và ceftriaxone. Kết quả phiên giải theo CLSI M100-S30 (Clinical Laboratory Standards Institute). ${ }^{6}$ Do CLSI chỉ định nghĩa điểm nhạy cảm cefixime và ceftriaxone là $\mathrm{MIC} \leq 0,25 \mathrm{mg} / \mathrm{L}$ nên kết quả MIC > 0,25mg/L được xác định là kháng. Kết quả kháng sinh đồ thu được 35 chủng lậu kháng ceftriaxone và cefixime.

35 chủng lậu này được bảo quản trong skim milk và vận chuyển có bảo quản lạnh bằng đá khô tới Đơn vị nghiên cứu lâm sàng Đại học Oxford Hà Nội (Oxford University Clinical Research Unit - OUCRU) để nuôi cấy lại trên môi trường GC của Oxoid bổ sung Vitox và hemoglobin đông khô đồng thời phân lập, định danh lại bằng hệ thống MalditoF. Sau khi được khẳng định chẩn đoán, 35 chủng lậu được làm lại kháng sinh đồ với 07 loại kháng sinh do WHO khuyến cáo là penicillin, tetracyclin, ciprofloxacin, spectinomicin, azithromycin, ceftriaxone và cefixime. Trong đó, Etest (Biomerieux) đối với azithromycin, cefixime và ceftriaxone. Kết quả kháng sinh đồ phiên giải theo CLSI M100-S30. Chủng chuẩn ATCC 49226 được làm kháng sinh đồ đối chiếu để nội kiểm chất lượng khoanh giấy, thanh Etest và môi trường thạch. Sau khi được khẳng định tính kháng với ceftriaxone và cefixime trên kháng sinh đồ, 35 chủng được giải trình tự toàn bộ gen bằng máy Miseq với kit 600 V3 (illumina, USA).

\section{Các biến nghiên cứu}

Đặc điểm nhân khẩu học (tuổi, giới) và yếu tố nguy cơ (hành vi tình dục, số lượng bạn tình, nguồn lây) và kết quả điều trị.

Phân loại trình tự (ST - sequence type) NG theo MLST, NG-MAST và NG STAR.

Gen kháng ESC: $m t r R$, mtrR promotor, penA, porB1b, porB3, rpoB, ponA, porA và porB1a (lần lượt khảo sát theo các gen chứng: $m$ trR.WHO_Y_01506, mtrR_promoter.WHO_F, penA47.001, porB1b.WHO_P_02204c, porB3. Neisseria_meningitidis_serogroup_A_Z2491_ v1_00376,rpoB.WHO_M_02157).

Đột biến mới và đã biết của các gen kháng.

\section{Xử lý số liệu}

Chúng tôi sử dụng fastp v.0.20.0 để lọc các bases chất lượng thấp và cắt bỏ các adapter. Phần mềm Shovill v.1.1.0 (https://github.com/ tseemann/shovill) và SPades v.3.14 để cấu trúc genome thành các contig từ các đoạn trình tự 
(reads) sinh ra từ máy giải trình tự Miseq. Sau đó, phần mềm MOB-suite v.3.0.0 xác định cấu trúc nhiễm sắc thể và plasmid NG từ các contig.

Phần mềm ARIBA 2.14.6 (https://github. com/martinghunt/ariba publication/tree/master/N_gonorrhoeae) để sàng lọc các gen kháng kháng sinh và đột biến. Phân loại trình tự đa loci (multi locus sequence type - MLST) để phân loại chủng NG sử dụng PubMLST. ${ }^{7}$ Chúng tôi phân loại trình tự đa kháng nguyên

\section{KÉT QUẢ}

Trong 35 chủng kháng ESC có 5 chủng từ Hà Nội, 26 chủng từ Thành phố Hồ Chí Minh và 4 chủng từ Đà Nẵng. Mức độ kháng ceftriaxone của nhóm chủng này tương đương các chủng vi khuẩn lậu (NG multi antigen sequence type - NG-MAST) bằng NGMaster v0.5.5 và phân loại chủng lậu theo 7 gen kháng (NG sequence typing for antimicrobial resistance - NG STAR) bằng pyngSTar.

\section{4. Đạo đức nghiên cứu}

Nghiên cứu được Hội đồng Đạo đức Nghiên cứu $Y$ sinh học, Trường Đại học $Y$ Hà Nội chấp thuận theo QĐ số 518/GCN-HĐĐĐNCYSHĐHYHN ngày 17/5/2021.

FC428 được báo cáo toàn cầu ( $\mathrm{MIC}$ : 0,5 - 1 mg/L) nhưng mức kháng thấp hơn với cefixime (MIC: 0,5 - 1,5 mg/L tại Việt Nam so với 1 - 4 $\mathrm{mg} / \mathrm{L}$ trên thế giới) ${ }^{8}$

\section{Phân loại chủng NG theo MLST, NGSTAR và NG-MAST}

Bảng 1. Tần suất các chủng lậu phân loại theo MLST và NG - MAST trên 35 chủng kháng cephalosporin

\begin{tabular}{|c|c|c|c|c|c|}
\hline $\begin{array}{c}\text { ST } \\
\text { (MLST) }\end{array}$ & $\begin{array}{c}\text { Tần suất } \\
\text { n (\%) }\end{array}$ & $\begin{array}{c}\text { ST } \\
\text { (NG-MAST) }\end{array}$ & $\begin{array}{c}\text { Tần suất } \\
\text { n (\%) }\end{array}$ & $\begin{array}{c}\text { ST } \\
\text { (NG-STAR) }\end{array}$ & $\begin{array}{c}\text { Tần suất } \\
\text { n (\%) }\end{array}$ \\
\hline 1901 & $13(37,1)$ & Mới & $13(37,1)$ & Chưa xác định & $28(80)$ \\
\hline 13871 & $11(31,4)$ & 16337 & $11(31,4)$ & 233 & $5(14)$ \\
\hline 7363 & $4(11)$ & 7237 & $4(11)$ & 1133 & $1(2,8)$ \\
\hline 13732 & $2(5)$ & 20094 & $2(5)$ & 1232 & $1(2,8)$ \\
\hline 8143 & $1(2,8)$ & 1086 & $1(2,8)$ & & \\
\hline 13333 & $1(2,8)$ & 5061 & $1(2,8)$ & & \\
\hline 1588 & $1(2,8)$ & & & & \\
\hline 1587 & $1(2,8)$ & & & & \\
\hline Mới & $1(2,8)$ & & & & \\
\hline
\end{tabular}

Theo phân loại MLST, 35 mẫu phân thành 9 nhóm lậu (ST) khác nhau, trong đó phổ biến là ST1901 $(37,1 \%)$ và ST13871 $(31,4 \%)$. ST1901 có 13 chủng: 1 ở Hà Nội, 1 ở Đà năng và 11 ở tp HCM. ST13871 có 11 chủng: 3 ở Đà Nẵng và 8 ở tp HCM. Có một ST mới chưa được mô tả, trong khi các ST khác chiếm tỷ lệ thấp (ST7363: 4\%, ST13732: 2\%). (Bảng 1)

Theo phân loại NG-MAST, có 6 nhóm ST khác nhau, trong đó có một ST mới chưa được mô tả. Có 11 chủng thuộc ST16337 (31,4\%), 4 chủng ST7237 (11,4\%) và 2 chủng ST20092 $(5,7 \%)$. 
ST1086 và ST5061 có tỷ lệ thấp (Bảng 1).

Theo phân loại NGSTART, 28 chủng có ST chưa được mô tả, 5 chủng thuộc ST233, 1 chủng thuộc ST1133 và 1 chủng thuộc ST1232.

(Bảng 1).

2. Gen kháng và các đột biến

Bảng 2. Các gen kháng thuốc phát hiện trên 35 chủng lậu kháng cephalosporin

\begin{tabular}{|c|c|c|c|}
\hline Gen kháng & Đặc điểm của gen đột biến & $\begin{array}{l}\text { Số chủng } \\
\text { phát hiện }\end{array}$ & Gen chứng \\
\hline 16S.rDNA & Kháng với Spectinomycin & 35 & 16S.rDNA_WHO_F_01361c \\
\hline 23S.rDNA & $\begin{array}{c}\text { Kháng với Macrolides } \\
\text { (azithromycin, erythromycin) }\end{array}$ & 35 & 23S.rDNA_WHO_F_01358c \\
\hline blaTEM & $\begin{array}{l}\text { Gen trên plasmid gây kháng } \\
\text { penicillin }\end{array}$ & 17 & $\begin{array}{l}\text { blaTEM.WHO_M_ } \\
\text { pConjugative_00003 }\end{array}$ \\
\hline gyrA & $\begin{array}{l}\text { Kháng với Quinolon (ciproploxacin, } \\
\text { ofloxacin) }\end{array}$ & 30 & gyrA.WHO_M_01098 \\
\hline $\mathrm{mtrR}$ & $\begin{array}{l}\text { Kháng Penicillin, Tetracyclines, } \\
\text { Macrolides, Cephalosporins }\end{array}$ & 26 & mtrR.WHO_Y_01506 \\
\hline mtrR_promoter & $\begin{array}{l}\text { Kháng Penicillin, Tetracyclines, } \\
\text { Macrolides, Cephalosporins }\end{array}$ & 35 & mtrR_promoter.WHO_F \\
\hline parC & $\begin{array}{l}\text { Kháng với Quinolon (ciproploxacin, } \\
\text { ofloxacin) }\end{array}$ & 26 & parC.WHO_Y_00247c \\
\hline penA & $\begin{array}{c}\text { Kháng với các kháng sinh nhóm } \\
\text { beta-lactam }\end{array}$ & 35 & penA. \\
\hline ponA & Kháng với Penicillin & 35 & ponA.WHO_G_00106 \\
\hline porB1b & $\begin{array}{l}\text { Kháng với Penicillin, Tetracyclines, } \\
\text { Macrolides, Cephalosporins }\end{array}$ & 14 & porB1b.WHO_P_02204c \\
\hline rpoB & Kháng với Cephalosporins & 34 & rpoB.WHO_M_02157 \\
\hline rps J & Kháng với Tetracycline & 35 & rpsJ.WHO_Y_02241 \\
\hline porB1a & Kháng với Cephalosporin & 6 & porB1a.WHO_N_02200c \\
\hline porB3 & Kháng với Cephalosporin & 4 & $\begin{array}{l}\text { porB3.Neisseria_meningitidis_ } \\
\text { serogroup_A_Z2491_v1_00376 }\end{array}$ \\
\hline folP & Kháng với Sulfonamides & 18 & folP.WHO_Y_01480c \\
\hline tetM & $\begin{array}{c}\text { Gen trên plasmid gây kháng với } \\
\text { Tetracycline }\end{array}$ & 3 & tetM.WHO_G_pTetM_00047 \\
\hline
\end{tabular}

Chúng tôi xác định được 16 gen gây tính kháng kháng sinh. Trong đó, 6 gen chính liên quan đến kháng cephalosporin là gen penA, $m t r R$ và yếu tố xác định tính kháng penB (gen PorB1b), porB, rpoB và ponA (Bảng 2). 
Bảng 3. Các đột biến của gen kháng ESC trên 35 chủng lậu

\begin{tabular}{|c|c|c|c|c|c|}
\hline Gen kháng & Chức năng của gen & $\begin{array}{l}\text { Đột biến } \\
\text { đã biết }\end{array}$ & $\begin{array}{l}\text { Số chủng } \\
\text { phát hiện }\end{array}$ & Đột biến móoi & $\begin{array}{l}\text { Số chủng } \\
\text { phát hiện }\end{array}$ \\
\hline \multirow{2}{*}{$\mathrm{mtrR}$} & $\begin{array}{c}\text { Điều hòa hoạt động bơm } \\
\text { bơm thải MtrCDE. Đột } \\
\text { biến gen này làm tăng }\end{array}$ & G45D & 26 & A39T & 3 \\
\hline & $\begin{array}{c}\text { hoạt động bơm gây thải } \\
\text { kháng sinh ra khỏi tế bào } \\
\text { vi khuẩn }\end{array}$ & & & Y105H A127fs & 1 \\
\hline $\begin{array}{c}\text { mtrR } \\
\text { promoter }\end{array}$ & $\begin{array}{c}\text { Khởi động } \\
\text { sao mã gen mtrR }\end{array}$ & $-35 \mathrm{~A}$ del & 24 & & \\
\hline \multirow{4}{*}{ penA 60.001} & \multirow{4}{*}{$\begin{array}{c}\text { Mã hóa protein Penicillin } \\
\text { Binding Protein } 2 \text { (PBP2). } \\
\text { Protein này là đích tác } \\
\text { động của beta-lactam }\end{array}$} & $\begin{array}{l}\text { A311V } \\
\text { G545S } \\
\text { I312M } \\
\text { T316P } \\
\text { V316T } \\
\text { A501P } \\
\text { A501V } \\
\text { P551S }\end{array}$ & 26 & $\begin{array}{c}\text { N512Y } \\
\text { P552V } \\
\text { K555Q } \\
\text { I556V } \\
\text { T573_ } \\
\text { A574insN } \\
\text { A574V }\end{array}$ & 26 \\
\hline & & T483S & 11 & $\begin{array}{l}\text { A480P } \\
\text { T534A }\end{array}$ & 15 \\
\hline & & & & $\begin{array}{l}\text { A328P } \\
\text { T483S } \\
\text { T485I }\end{array}$ & 11 \\
\hline & & & & $\begin{array}{c}\text { A957G } \\
\text { T930G } \\
\text { C900T, A } \\
\text { T945C, G } \\
\text { T918C, G }\end{array}$ & 1 \\
\hline
\end{tabular}




\begin{tabular}{|c|c|c|c|c|c|}
\hline Gen kháng & Chức năng của gen & $\begin{array}{c}\text { Đột biến } \\
\text { đã biết }\end{array}$ & $\begin{array}{l}\text { Số chủng } \\
\text { phát hiện }\end{array}$ & Đột biến mới & $\begin{array}{l}\text { Số chủng } \\
\text { phát hiện }\end{array}$ \\
\hline penA 10.001 & & A311V & 2 & $\begin{array}{c}\text { T1194C } \\
\text { A1197G } \\
\text { T1191C } \\
\text { V279A } \\
\text { E285D } \\
\text { K288R } \\
\text { Q291R } \\
\text { A328P } \\
\text { H201Y } \\
\text { A202G } \\
\text { G203E } \\
\text { E204D } \\
\text { E214Q }\end{array}$ & 1 \\
\hline
\end{tabular}

\begin{tabular}{|c|c|c|c|c|}
\hline & V316T & & & \\
\hline & T316P & & & \\
\hline & T483S & & & \\
\hline & A501V & 1 & & \\
\hline & A501P & 1 & & \\
\hline & G542S & & & \\
\hline & G545S & & & \\
\hline & P551S & & & \\
\hline \multirow{9}{*}{ penA 124.001} & A311V & \multirow{9}{*}{1} & & \multirow{9}{*}{1} \\
\hline & I312M & & S341P & \\
\hline & T316P & & A480P & \\
\hline & V316T & & T534A & \\
\hline & A501V & & Q555K & \\
\hline & A501P & & N562K & \\
\hline & G542S & & L564V & \\
\hline & G545S & & G565S & \\
\hline & P551S & & V575A & \\
\hline \multirow{8}{*}{ penA 166.001} & A311V & \multirow{8}{*}{1} & \multirow{8}{*}{$\begin{array}{l}\text { A480P } \\
\text { N512Y } \\
\text { T534A } \\
\text { T573_- } \\
\text { A574insN } \\
\text { A574V }\end{array}$} & \multirow{8}{*}{1} \\
\hline & G545S & & & \\
\hline & I312M & & & \\
\hline & T316P & & & \\
\hline & V316T & & & \\
\hline & A501V & & & \\
\hline & A501P & & & \\
\hline & P551S & & & \\
\hline
\end{tabular}




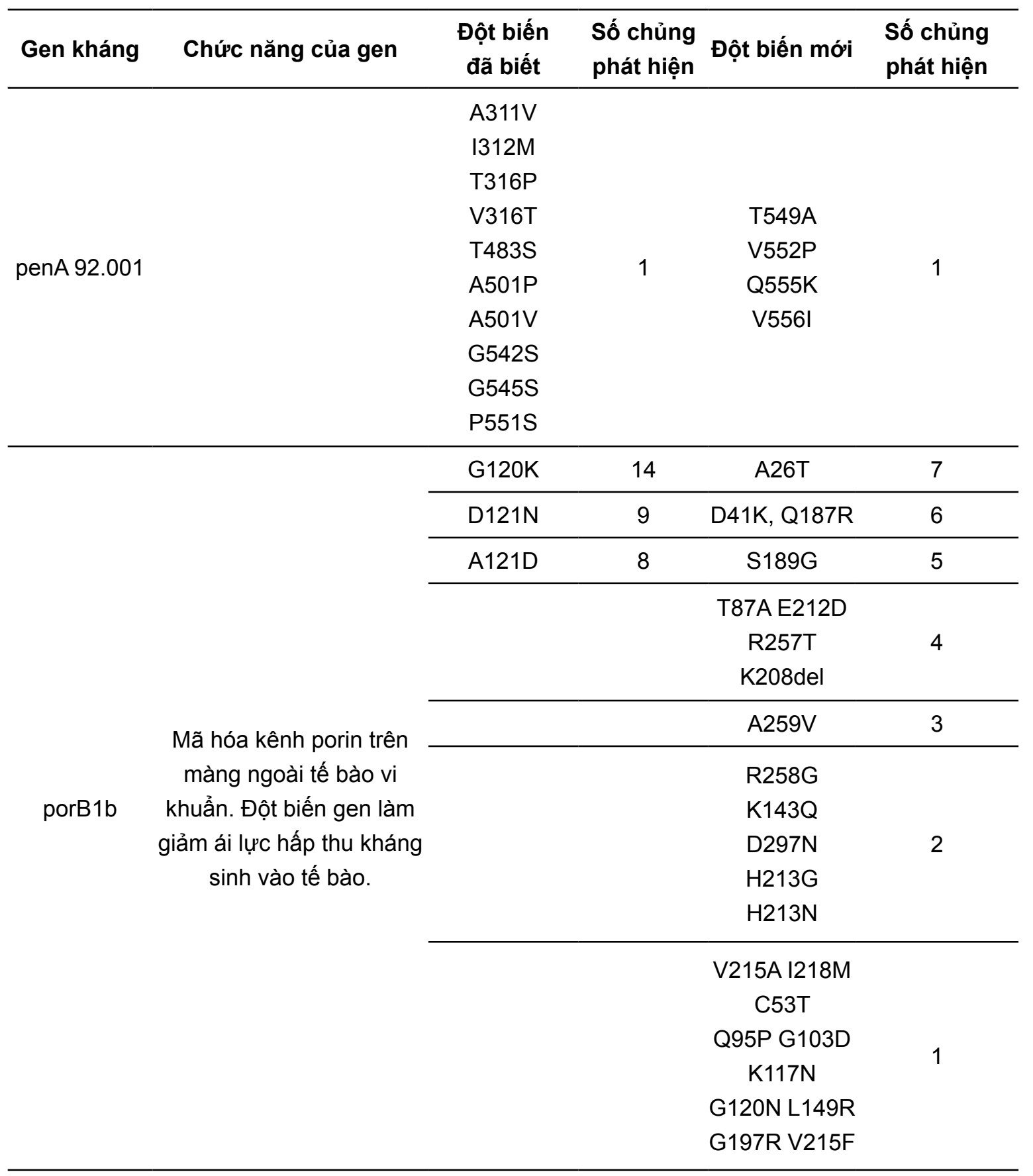




\begin{tabular}{|c|c|c|c|c|c|}
\hline Gen kháng & Chức năng của gen & $\begin{array}{l}\text { Đột biến } \\
\text { đã biết }\end{array}$ & $\begin{array}{l}\text { Số chủng } \\
\text { phát hiện }\end{array}$ & Đột biến mó'i & $\begin{array}{l}\text { Số chủng } \\
\text { phát hiện }\end{array}$ \\
\hline \multirow[b]{2}{*}{ porB3 } & \multirow{2}{*}{$\begin{array}{c}\text { Mã hóa kênh porin trên } \\
\text { màng ngoài tế bào vi } \\
\text { khuẩn. Đột biến gen làm } \\
\text { giảm ái lực hấp thu kháng } \\
\text { sinh vào tế bào. }\end{array}$} & & & $\begin{array}{c}\text { M18T T29A } \\
\text { E32Q S34Y } \\
\text { L253A S273T } \\
\text { R279H E313A } \\
\text { N314D F316I }\end{array}$ & 2 \\
\hline & & & & $\begin{array}{c}\text { S217G } \\
\text { D222N A226V } \\
\text { V230A } \\
\text { V238Y E239G } \\
\text { K278N D276S } \\
\text { K278D }\end{array}$ & 1 \\
\hline rроB & Mã hóa RNA polymerase & H553N & 10 & $\begin{array}{c}\text { E7V } \\
\text { K9I } \\
\text { S14R F15C } \\
\text { K17T } \\
\text { V24G P25S } \\
\text { D1366Y } \\
\text { G1368V } \\
\text { P1033fs }\end{array}$ & 1 \\
\hline ponA & Mã hóa protein PBP1 & L421P & 30 & $\begin{array}{c}\text { A375T } \\
\text { Q422E S427P } \\
\text { K431N A437fs } \\
\text { K447Q F463C } \\
\text { L6V } \\
\text { G64V }\end{array}$ & 2 \\
\hline
\end{tabular}

Liên quan gen penA, allen khảm penA 60.001 xuất hiện ở $26 / 35$ chủng $(74,2 \%)$ có 9 đột biến thay đổi acid amin đã biết trong đó 6 đột biến chính gây kháng ESC: A311V, T483S, A501P, G545S, I312M và V316T. 18 đột biến mới bao gồm: N512Y, G545S, P552V, K555Q, I556V, T573_A574insN, A574V: 26 chủng (100\%), A480P và T534A: 15/26 chủng (57,6\%). A328P, T483S, T485I: 11/26 chủng (42,3\%). Các đột biến khác chiếm tỷ lệ thấp.
Allen khảm penA 10.001 xuất hiện ở 4/35 chủng $(11,4 \%)$, có 9 đột biến đã biết bao gồm các đột biến chính gây kháng ESC và 13 đột biến mới với tần suất thấp. Alen penA 124.001 xuất hiện ở $3 / 35$ chủng $(8,6 \%)$ với 9 đột biến đã biết và 8 đột biến mới. Allen khảm penA 166.001 xuất hiện ở 1 chủng với 8 đột biến đã biết và 7 đột biến mới. Allen khảm penA 92.001 có 10 đột biến đã biết và 4 đột biến mới (Bảng 3). 
Đột biến gen $m$ trR xuất hiện ở 26/35 chủng (74,2\%). Trong đó, 1 đột biến đã biết G45D (26/35 chủng) và 3 đột biến mới A39T, Y105H và đột biến dịch khung $A 127 f$ s (frame shift) có tần suất thấp (Bảng 3 ).

Đột biến mất 1 nucleotide Adenin ở vùng -35 promoter của gen $m t R$ (-35Adel) dẫn đến tăng quá mức bơm thải MtrCDE xuất hiện ở 24/35 chủng (Bảng 3 ).

Gen porB1b (yếu tố xác định tính kháng penB) xuất hiện ở 14/35 chủng có 3 đột biến đã biết là G120K, A121D, D121N và 35 đột biến mới có tần suất thấp (Bảng 3).

Gen porB3 có ở 4/35 chủng có 19 đột biến mới với tần suất thấp (Bảng 3 ).

Gen rpoB xuất hiện ở cả 35 chủng có 10 đột biến mới (Bảng 3).

Yếu tố kháng 23SrDNA (kháng macrolid), 16SrDNA (kháng spectinomycin), gen rpsJ (kháng tetracyclin) và gen parE (kháng quinolon) xuất hiện ở cả 35 chủng, gen gyrA (kháng quinolon): 30 chủng, gen folP (kháng sulfamid): 18 chủng, gen blaTEM (kháng penicillin): 17 chủng (Bảng 3 ).

\section{3. Đặc điểm nhân khẩu học, điều trị và yếu tố liên quan ca bệnh}

Bảng 4. Đặc điểm nhân khẩu học và điều trị của 35 bệnh nhân nhiễm chủng lậu kháng Cephalosporin

\begin{tabular}{|c|c|c|c|}
\hline $\begin{array}{c}\text { Đặc điểm } \\
\text { nhân khẩu học }\end{array}$ & n (\%) & Đặc điểm dịch tễ & n (\%) \\
\hline Giới tính & & $\begin{array}{c}\text { Số bạn tình } \\
\text { trong vòng } 3 \text { tháng }\end{array}$ & \\
\hline Nam & $32(91,4)$ & 1 & $12(34,3)$ \\
\hline Nưr & $3(8,6)$ & $\geq 2$ & $23(65,7)$ \\
\hline Tuổi (Trung bình) & $20-56(32,63)$ & Tiền sử mắc STD & 0 \\
\hline Tình trạng hôn nhân & & $\begin{array}{l}\text { Quan hệ tình dục với } \\
\text { người bán dâm }\end{array}$ & $7(33)$ \\
\hline Độc thân & $16(45,7)$ & $\begin{array}{c}\text { Quan hệ tình dục không } \\
\text { dùng bao cao su }\end{array}$ & $28(80)$ \\
\hline Có vợ/chồng & $19(54,3)$ & $\begin{array}{c}\text { Quan hệ tình dục } \\
\text { đồng giới }\end{array}$ & 0 \\
\hline $\begin{array}{l}\text { Đặc điểm điều trị } \\
\text { Hết triệu chứng trong } \\
\text { vòng } 2 \text { tuần sau điều trị } \\
\text { phác đồ WHO }\end{array}$ & $35(100)$ & $\begin{array}{l}\text { Nguồn lây: } \\
\text { Vợ/chồng: } \\
\text { Bạn tình: } \\
\text { Người bán dâm }\end{array}$ & $\begin{array}{c}3(8,6) \\
21(60) \\
11(31,4)\end{array}$ \\
\hline
\end{tabular}

STD: Sexually Transmitted Diseases (Bệnh truyền qua đường tình dục); QHTD; Quan hệ tình dục

Nam giới chiếm đa số mẫu bệnh phẩm trong nghiên cứu $(91,4 \%)$ Tuổi trung bình là 32,63 tuổi (20 - 56) (Bảng 4).

Liên quan hành vi nguy cơ, $65,7 \%$ số bệnh nhân có từ 2 bạn tình trở lên trong vòng 3 tháng. 
$33 \%$ số bệnh nhân có quan hệ tình dục với người bán dâm, $80 \%$ không sử dụng bao cao su trong lần quan hệ tình dục lây bệnh, 91,4\% lây bệnh từ quan hệ tình dục ngoài hôn nhân. Các bệnh nhân không có tiền sử mắc bệnh lây qua đường tình dục tại thời điểm chẩn đoán bệnh lậu (Bảng 4).

Tất cả 35 bệnh nhân hết triệu chứng trong vòng 2 tuần sau điều trị theo phác đồ của WHO (Bảng 4).

\section{BÀN LUẬN}

Năm 2015, Shimuta và cộng sự khảo sát các chủng NG thu thập từ 1995 - 2005 ở Nhật Bản đã phát hiện một chủng kháng cefixime đầu tiên. ${ }^{9}$ Từ năm 1996 trở đi, các chủng giảm nhạy cảm hoặc kháng cefixime tăng nhanh và đạt đỉnh năm 2002. Giai đoạn 1997 - 2002, chủng kháng cefixime MLST7363 mang allen khảm penA 10.001 chiếm ưu thế. Sau đó, chủng mới thuộc MLST1901 mang allen khảm penA 34 gây kháng cefixime và được xác định lần đầu tại Nhật Bản. ${ }^{9}$ Chủng MLST1901 kháng cefixime lây lan nhanh: năm 2010 tại Pháp (chủng F89) gây kháng trị với cefixime, năm 2011 tại Tây Ban Nha, năm 2013 tại Úc (A8806) và năm 2014 tại Nhật Bản (GU140106). ${ }^{10,11}$ Nhóm 35 chủng kháng ESC trong nghiên cứu này có 13 chủng $(37,1 \%)$ thuộc ST1901 mang allen khảm penA 60.001 .

Từ 2015 - 2017, Nhật Bản xác định 6 chủng kháng ceftriaxone bao gồm FC428, FC460, FC498, KU16054, KM383 và KU17039. ${ }^{12}$ Năm 2017, chủng FC428 lan sang Úc (A7536, A7846), Canada (47707), Đan Mạch (GK124) và Pháp (F90) và năm 2018 lan sang Ireland (IR72). ${ }^{4}$ Chủng FC428 thuộc MLST1903 phát triển các nhánh (clade) trong đó có chủng NG kháng ESC MLST13871. Chủng ST13871 đầu tiên trên thế giới được xác định tại Singapore và Pháp lần lượt vào các năm 2018, 2019.13,14
Tại Việt Nam, trong số 229 chủng thu thập năm 2011 và 2015 - 2016 và hơn 300 chủng thu thập năm 2017 - 2018 không có chủng nào thuộc ST13871. ${ }^{15,16}$ Trong nghiên cứu này, chúng tôi có 11/35 chủng kháng ESC thuộc ST13871 (34\%). Các chủng này phân bố chủ yếu ở phía nam Việt Nam. Nhiều ca bệnh lậu nhiễm chủng gần với chủng FC428 có mạng lưới tình dục tại Châu Á, nhất là khu vực Đông Nam Á. Vì vậy, Đông Nam Á là khu vực nguy cơ cao lan truyền các chủng lậu kháng ESC.

Khảo sát 108 chủng NG của Việt Nam năm 2011 ghi nhận 75 loại ST khác nhau theo phân loại trình tự NG - MAST, trong đó 59 trình tự chưa được mô tả. ${ }^{15}$ Nghiên cứu của chúng tôi tập trung vào nhóm chủng NG kháng ESC nên có cỡ mẫu nhỏ và chỉ ghi nhận 6 trình tự NG MAST trong đó có một trình tự mới.

Theo hệ thống NG STAR dựa vào 7 gen kháng đặc trưng của vi khuẩn lậu, đa số chủng trong nghiên cứu này chưa xác định được $S T$, có 5/35 chủng thuộc ST233.

Năm 2011, PT Lan và cộng sự khảo sát các yếu tố kháng ESC (gen penA, mtrR và penB) của 108 chủng lậu tại Việt Nam. Kết quả không có chủng nào mang allen khảm penA. Tuy nhiên, $78 \%$ chủng chứa đột biến A501 là A501V (44\%) và $\mathrm{A} 501 \mathrm{~T}$ (34\%) trên PBP2. 91\% chủng mang đột biến mất Adenin trên $m t r R$ promoter và $94 \%$ chủng mang đột biến trên gen $m t r R{ }^{15}$ Năm 2015 - 2016, PT Lan khảo sát 121 chủng tại Việt Nam thấy $27 \%$ chủng chứa một allen khảm penA. Phân tích phả hệ gen thấy xuất hiện mới 2 nhóm chủng (clone) chứa gen khảm penA từ sau năm 2011 (penA 10.001 và penA 34.001). ${ }^{16}$ Trong số 35 chủng kháng $\mathrm{ESC}$, chúng tôi thấy $74 \%$ chủng mang allen khảm penA 60.001, $11 \%$ mang allen khảm penA 10.001 với 9 đột biến đã biết, trong đó đột biến A311V, T483S, A501P, G545S, I312M và V316T là những đột biến chính gây kháng ESC thông qua biến đổi 
cấu trúc phân tử PBB2. Ngoài ra, gen penA có nhiều đột biến mới. Yếu tố kháng này liên quan đến chủng kháng cefixime lây lan ở Nhật Bản và nhiều khu vực trên thế giới. Các chủng gần với chủng FC428 được báo báo rộng rãi đặc biệt là clone kháng ESCs do các đột biến trên một allen khảm penA 60.001. Chúng gây lo ngại về nguy cơ kháng trị với ESC trong thời gian tới.

Chúng tôi thấy gen $m t r R$ xuất hiện ở $74,2 \%$ chủng và đột biến $m t R$ promoter ở $100 \%$ chủng. Đây là những yếu tố gây đa kháng (ESC, marcolid, penicillin và tetracyclin) ở vi khuẩn lậu. Trong đó, độ biến -35Adel trên $m t r R$ promoter dẫn đến bộc lộ quá mức bơm thải MtrCDE khiến tăng đào thải kháng sinh ra khỏi vi khuẩn. Đặc điểm về gen kháng ECS ở 35 chủng trong nghiên cứu này phù hợp với kết quả khảo sát 65 chủng NG (2011 - 2014) tại Ý khi thấy allen khảm penA 34 và penA 35 có mặt ở hầu hết các chủng kháng hoặc giảm nhảy cảm cefixime. Cùng với đột biến -35 Adel trên $m t r R$ promoter, đột biến thay đổi acid amin H105Y hoặc G45D trên gen $m t r R$ và L421P trên gen ponA phối hợp linh hoạt làm thay đổi MIC cefixime trên thực nghiệm. ${ }^{17}$

35 ca bệnh đều đáp ứng với điều trị với phác đồ phối hợp ceftriaxone/cefixime + azithromycin, đánh giá dựa vào cải thiện triệu chứng trên lâm sàng. Tuy nhiên, việc xuất hiện mới các chủng liên quan tới chủng kháng ESC quốc tế tại Việt Nam cho thấy vi khuẩn lậu kháng ESC đang gia tăng tại Việt Nam. Hơn nữa, để đánh giá hiệu quả tiêu diệt vi khuẩn, chúng tôi cân nhắc đề suất xét nghiệm vi khuẩn sau 3 tuần điều trị. Việc thu thập thông tin về dịch tễ học cũng quan trọng giúp xác định mạng lưới lây truyền các chủng lậu. Điều này cần thiết để kiểm soát các chủng lậu kháng thuốc tại Việt Nam.

\section{KÉT LUẦN}

Các nhóm NG phổ biến trong nghiên cứu này (ST1901 và ST 13871) chủ yếu phân bố ở phía nam Việt Nam, liên quan đến chủng kháng ESC phát hiện đầu tiên tại Nhật Bản và hiện đã lan rộng nhiều nơi trên thế giới. Phần lớn các chủng mang yếu tố kháng allen khảm penA 60.001, penA 10.001 và $\mathrm{mtrR} / \mathrm{mtrR}$ promoter với các đột biến kháng ESC đặc trưng đồng thời có thêm nhiều đột biến mới.

\section{LỜ' CẢM O'N}

Nghiên cứu này được tài trợ bởi Oucru Hà Nội và WHO. Các đơn vị hợp tác gồm có Ourcu, Bệnh viện Da liễu Trung ương, Bệnh viện $\mathrm{Da}$ liễu $T p$ Hồ $C h i$ Minh và Bệnh viện $\mathrm{Da}$ liễu Đà Nẵng.

\section{TÀI LIẸU THAM KHẢO}

1. Unemo M, Shafer WM. Antimicrobial resistance in Neisseria gonorrhoeae in the 21st century: past, evolution, and future. Clin Microbiol Rev. 2014;27(3):587-613. doi:10.1128/CMR.00010-14

2. George CRR, Enriquez RP, Gatus BJ, et al. Systematic review and survey of Neisseria gonorrhoeae ceftriaxone and azithromycin susceptibility data in the Asia Pacific, 2011 to 2016. PloS One. 2019;14(4):e0213312. doi:10.1371/journal.pone.0213312

3. Ohnishi M, Golparian D, Shimuta K, et al. Is Neisseria gonorrhoeae initiating a future era of untreatable gonorrhea?: detailed characterization of the first strain with highlevel resistance to ceftriaxone. Antimicrob Agents Chemother. 2011;55(7):3538-3545. doi:10.1128/AAC.00325-11

4. Lee K ichi, Nakayama SI, Osawa K, et al. Clonal expansion and spread of the ceftriaxoneresistant Neisseria gonorrhoeae strain FC428, identified in Japan in 2015, and closely related isolates. J Antimicrob Chemother. 2019;74:1812-1819. doi:10.1093/jac/dkz129 
5. Adamson PC, Van Le H, Le HHL, Le GM, Nguyen TV, Klausner JD. Trends in antimicrobial resistance in Neisseria gonorrhoeae in Hanoi, Vietnam, 2017-2019. BMC Infect Dis. 2020;20(1):809. doi:10.1186/s12879-02005532-3

6. m100ed30_sample.pdf. Accessed September 10, 2021. https://clsi.org/media/3481/ m100ed30_sample.pdf

7. Neisseria spp. PubMLST. Accessed August 8, 2021. https://pubmlst.org/organisms/ neisseria-spp.

8. Yan J, Chen Y, Yang F, et al. High percentage of the ceftriaxone-resistant Neisseria gonorrhoeae FC428 clone among isolates from a single hospital in Hangzhou, China. $J$ Antimicrob Chemother. 2021;76(4):936-939. doi:10.1093/jac/dkaa526.

9. Shimuta K, Watanabe Y, Nakayama $S$ ichi, et al. Emergence and evolution of internationally disseminated cephalosporinresistant Neisseria gonorrhoeae clones from 1995 to 2005 in Japan. BMC Infect Dis. 2015;15:378. doi:10.1186/s12879-015-1110-x.

10. Unemo M, Nicholas RA. Emergence of multidrug-resistant, extensively drug-resistant and untreatable gonorrhea. Future Microbiol. 2012;7(12):1401-1422. doi:10.2217/fmb.12.117.

11. Lahra MM, Martin I, Demczuk W, et al. Cooperative Recognition of Internationally Disseminated Ceftriaxone-Resistant Neisseria gonorrhoeae Strain. Emerg Infect Dis. 2018;24(4). doi:10.3201/eid2404.171873.

12. Nakayama SI, Shimuta K, Furubayashi KI, Kawahata T, Unemo M, Ohnishi M. New
Ceftriaxone- and Multidrug-Resistant Neisseria gonorrhoeae Strain with a Novel Mosaic penA Gene Isolated in Japan. Antimicrob Agents Chemother. 2016;60(7):4339-4341. doi:10.1128/AAC.00504-16.

13. Ko KKK, Chio MTW, Goh SS, Tan AL, Koh TH, Abdul Rahman NB. First Case of Ceftriaxone-Resistant Multidrug-Resistant Neisseria gonorrhoeae in Singapore. Antimicrob Agents Chemother. 2019;63(5):e02624-18. doi:10.1128/AAC.02624-18.

14. Poncin T, Merimeche $M$, Braille $A$, et al. Two cases of multidrug-resistant Neisseria gonorrhoeae related to travel in south-eastern Asia, France, June 2019. Euro Surveill Bull Eur Sur Mal Transm Eur Commun Dis Bull. 2019;24(36). doi:10.2807/1560-7917. ES.2019.24.36.1900528.

15. Olsen B, Pham TL, Golparian D, Johansson E, Tran HK, Unemo M. Antimicrobial susceptibility and genetic characteristics of Neisseria gonorrhoeae isolates from Vietnam, 2011. BMC Infect Dis. 2013;13:40. doi:10.1186/1471-2334-13-40.

16. Lan PT, Golparian D, Ringlander J, Van Hung L, Van Thuong N, Unemo M. Genomic analysis and antimicrobial resistance of Neisseria gonorrhoeae isolates from Vietnam in 2011 and 2015-16. J Antimicrob Chemother. 2020; 75(6):1432-1438. doi:10.1093/jac/dkaa040.

17. Carannante A, Vacca P, Ghisetti V, et al. Genetic Resistance Determinants for Cefixime and Molecular Analysis of Gonococci Isolated in Italy. Microb Drug Resist Larchmt N. 2017;23(2):247-252. doi:10.1089/ mdr.2016.0086. 


\section{Summary}

\section{MOLECULAR MECHANISM OF CEPHALOSPORIN RESISTANCE OF NEISSERIA GONORRHOEAE IN VIETNAM 2019 - 2020}

Cephalosporin-resistant Neisseria gonorrhoeae (NG) strains have been increasing. $35 \mathrm{NG}$ isolates

that resisted to cephalosporin on biogram collected from 3 hospitals of dermatology and venereology in Vietnam were whole genome sequenced to determine antimicrobial resistant (AMR) genes. There were 13/35 isolates belonged to ST1901, 11/35: ST 13871. There were 16 different AMR genes. $74 \%$ of the isolates possessed mosaic penA 60.001 and $11 \%$ mosaic penA 10.001. These penA allens contained 6 key mutations responsible for ESC resistance (A311V, T483S, A501P, G545S, I312M và $\mathrm{V} 316 \mathrm{~T}$ ) and some novel mutations. mtrR mutants was seen in $74.2 \%$ of the isolates. All of them had Adenine deletion mutation on $m t R$ promoter. The level of ceftriaxone resistance was relevant to FC428 strains but lower in cefixim resistance. The NG isolates (ST1901 and ST 13871) are related to cephalosporin-resistant strains detected in Japan that are currently spreading worldwide. Most of them possessed mosaic penA 60.001 and penA10.001, $\mathrm{mtrR} / \mathrm{mtrR}$ promoter. These AMR genes contained typical mutations responsible for cephalosporin resistance and different novel mutations.

Keywords: Cephalosporin,rr antimicrobial resistance, ARM genes, mutations, MLST... 